\title{
The Application of Garch Family Models for Agricultural Crop Products in Amhara Region, Ethiopia
}

\author{
Belayneh Debasu Kelkay $^{1^{\star}}$ and Emmanuel G/Yohannes ${ }^{2}$ \\ ${ }^{1}$ Department of Statistics, Arba Minch University, P.O. Box: 21, Arba Minch, Ethiopia \\ ${ }^{2}$ Ethiopian Civil Service University, P.O. Box: 5648, Addis Ababa, Ethiopia
}

\begin{tabular}{|c|c|}
\hline \multirow{11}{*}{$\begin{array}{l}\text { Abstract } \\
\text { In the recent past, the price of general commodities has increased in Ethiopia as well as in the } \\
\text { world. The main objective of this study is to identify and analyze the factors that affect the } \\
\text { average monthly price volatility of pulses (bean and pea) in Amhara National Regional State } \\
\text { over the period of December } 2001 \text { to June } 2012 \mathrm{GC} \text {. The return series considered exhibited } \\
\text { typical characteristics of financial time series such as volatility clustering, leptokurtic } \\
\text { distributions and asymmetric effect and thus, can suitably modeled using GARCH family } \\
\text { models. Among such models entertained in this study, ARMA }(4,4) \text {-EGARCH( }(2,3) \text { with GED } \\
\text { for bean and ARMA }(1,0) \text {-EGARCH }(1,2) \text { with student-t for pea were chosen to be the best fit } \\
\text { models. From the results, exchange rate and general and food inflation rates were found to be } \\
\text { an increasing effect on price volatility of bean and pea. On the other hand, rainfall was found } \\
\text { to have a stabilizing effect on the price volatility of these crops. Moreover, saving interest rate } \\
\text { has a decreasing effect on the price volatility of bean. The results also revealed that price } \\
\text { volatility has seasonal variation. The asymmetric terms were found to be significant in all } \\
\text { GARCH models considered. Thus, price volatility tends to over-react in response to bad news } \\
\text { as compared to good news. Furthermore, the significance of the EGARCH terms provides } \\
\text { strong evidence of volatility spillover from one period to another. }\end{array}$} & \\
\hline & Received : 25-08-2014 \\
\hline & : 13-12-2014 \\
\hline & $\begin{array}{l}\text { Accepted : 18-12-2014 } \\
\text { Keywords: }\end{array}$ \\
\hline & \\
\hline & \\
\hline & Amhara Region \\
\hline & family mo \\
\hline & \\
\hline & \\
\hline & \\
\hline
\end{tabular}

\section{INTRODUCTION}

In Ethiopia, agriculture accounts for almost $41 \%$ of the gross domestic product (GDP), $80 \%$ of exports, and $80 \%$ of the labor force. Many other economic activities depend on agriculture, including marketing, processing, and export of agricultural products. Production is overwhelmingly by small-scale farmers and enterprises and a large part of commodity exports are provided by the small agricultural cash-crop sector. Principal crops include coffee, pulses (e.g., bean and pea), oilseeds, cereals, potatoes, sugarcane and vegetables. Exports are almost entirely agricultural commodities, and coffee is the largest foreign exchange earner. In 2005/2006 Ethiopia's coffee exports represented $0.9 \%$ of the world export, and oil seeds and flowers each represent $0.5 \%$ (IMF, 2009).

Agricultural households in developing countries face a variety of risks. The most visible manifestation of these risks is high food price instability, which, because of its inherent economic and political implications, has attracted the attention of almost all actors in food policy making over the past few decades. However, all actors agree on one point, i.e. the direct consequences of price instability on consumers, producers, as well as on overall economic growth. For poor consumers, consequences of price instability are severe. Since a large share of their income is spent on food, an unusual price increase forces them to cut down food intake, take their children out of school, or, in extreme cases, simply to starve. Even when such price shocks are temporary, they can have long term economic impacts in terms of nutritional well-being, labor productivity, and survival chances (Hoddinott, 2006; Myers, 1993).

Variability in food prices can also have important effects even if average prices remain constant. This might happen if fluctuations in food production become more common or larger but average production remains the same. This would lead to more frequent and larger price changes, which might be predictable or unpredictable. If the increased variability were largely predictable, this would cause fewer problems than if the changes were unpredictable. However, price changes are generally less predictable than might be imagined. Unstable prices for staple foods are likely to have larger negative effects than unstable prices for other agricultural commodities because staple foods are important for both poor farmers and poor consumers. On the consumer side, staple foods account for a large share of the expenditures of the poor. On the producer side, they are the most widely planted crops in developing countries, especially on smallholdings (FAO, 2011).

It is crucial to examine the pattern of price volatility and identify its determinant on cereal crops. According to 


\section{Belayneh Debasu and Emmanueal G/Yohannes}

Jordaan et al. (2007), the accurate measurement of the stochastic component in prices may contribute to the decision maker being able to make more informed decisions when choosing one crop over another. It may also contribute to policy decisions regarding the possible implementation of commodity price stabilization programs. Examining the underlying causes of pulse price volatility has great role for managing price instability for producers, consumers, whole sellers and agricultural price policy reforms for the country as well.

In Amhara National Regional State (ANRS), agriculture contributed to about $55.8 \%$ of the total regional GDP. The main field crops in the Amhara region are cereals (wheat, barley, teff, sorghum, maize, etc), pulses (field pea, chickpea, bean, etc) and oil crops (sesame, rape seed, sunflower, etc). Cereals account for more than $80 \%$ of cultivated land and $85 \%$ of total crop production. About $33 \%$ of the livestock and $25-30 \%$ of crop production in Ethiopia are from the Amhara region (BoFED, 2011).

As many studies indicated price volatility of agricultural commodities has a negative impact on the economy of the country through income instability for producers, consumers and whole sellers and also leads to a major decline in future output if the price changes are unpredictable and erratic. Therefore, this study was an attempt to identify the pattern of average monthly price volatility of pulse seed (pea and bean) in Amhara Region by developing appropriate time series models that can fit financial data.

Therefore, this study has attempted to address the following problems (1) is there volatility in the price of some selected agricultural crops products (cereal and pulse seed)? (2) which agricultural commodities under consideration have highly volatile prices? (3) which model is a good fit to data on price of agricultural crop products?

The main objective of this study is to identify and analyze the factors that affect the price volatility of bean and pea seeds in Amhara Regional. Specifically, this study tries to address the following key issues (1) to fit and select an appropriate GARCH family models for the price volatility of pulse seeds (bean and pea), (2) to assess the pattern of their price volatility and (3) to estimate and forecast the price volatility of bean and pea seeds.

\section{MATERIALS AND METHODS}

\section{Source and Type of Data}

To assess the average monthly price volatility and its determinants on certain pulse seeds (beans and pea), the data were obtained from Central Statistical Agency (CSA), National Bank of Ethiopia (NBE) and National Metrological Agency of Ethiopia, on monthly basis from December 2001 to June 2012 G.C.

Average monthly price of pulse seed (bean and pea) is used as dependent variables. Exchange rate, saving interest rate, lending interest rate, general inflation rate, food inflation rate, non-food inflation rate, average temperature (in degree Celsius) and average rain fall (in $\mathrm{mm}$ ) are used as independent variables. Since the data are not seasonally adjusted also seasonal dummies are used.
Sci. Technol. Arts Res. J., Oct-Dec 2014, 3(4): 49-58

\section{(G) ARCH Models}

The Box-Jenkins time series model such as Autoregressive (AR), Moving Average (MA) and ARMA are often very useful in modeling general time series data. However, they all require the assumption of homoskedasticity (or constant variance) for the error term in the model. Autoregressive Conditional Heteroskedasticity (ARCH), separate GARCH, TGARCH and EGARCH models have been employed in this study to investigate the pattern of price volatility and its determinants.

\section{Model Specification: Stationarity and Unit-Root Problem}

A given series is said to be stationary if its mean and variance are constant overtime and the value of the covariance between any two time periods depends only on the distance or gap or lag between the two time periods and not the actual time at which the covariance is computed.

Generally the concept of stationarity can be summarized by the following conditions. A time series $\left\{y_{t}\right\}$ is said to be stationary if:

$$
\begin{gathered}
E\left(y_{t}\right)=E\left(y_{t-s}\right)=\mu, \\
E\left(y_{t}-\mu\right)^{2}=E\left(y_{t-s}-\mu\right)^{2}=\sigma_{y}^{2}, \\
E\left(y_{t}-\mu\right)\left(y_{t-s}-\mu\right)=E\left(y_{t-j}-\mu\right)\left(y_{t-j-s}-\mu\right)=\gamma(s),
\end{gathered}
$$

where $\mu, \sigma_{\mathrm{y}}{ }^{2}$ and $\mathrm{\gamma}(\mathrm{s})$ are all time invariant.

The assumption of stationarity is somewhat unrealistic for most macro economic variables. A non-stationary process arises when at least one of the conditionsfor stationarity does not hold. Let us consider an autoregressive process of order one (AR (1) process):

$$
\mathrm{y}_{\mathrm{t}}=\rho \mathrm{y}_{\mathrm{t}-1}+\varepsilon_{\mathrm{t}}
$$

where $\varepsilon_{t}$ denotes a serially uncorrelated white noise error term with a mean of zero and a constant variance. Non-stationarity can originate from various sources but the most important one is the presence of so-called "unit roots". Equation (1) is said to be a unit root process when $\rho=1$.

If a variable is stationary in level, i.e. without running any differencing, then the variable is said to be integrated of order zero, denoted by $I(0)$. Similarly, if it becomes stationary by differencing $d$ times, then the variable is said to be integrated of order $d$, written as $\mathrm{I}(\mathrm{d}), \mathrm{d}=1,2,3, \ldots$. Unit-root test helps to detect whether a variable is stationary or not. It also provides the order of integration at which the variable can be stationary.

Let $p_{t}, t=1,2,3 \ldots$ be the price of a commodity at time period $t$ ( $t$ in days, months, etc). Instead of analyzing $p_{t}$, which often displays unit-root behavior and thus cannot be modeled as stationary, we often analyze log- returns on $p_{t}$ (Fryzlewicz, 2007):

$$
Y_{t}=\log p_{t}-\log p_{t-1}=\log \left(\frac{p_{t}}{p_{t-1}}\right)=\log \left(1+\frac{p_{t}-p_{t-1}}{p_{t}}\right) .
$$

The series $y_{t}$, log- return series, displays many of the typical characteristics in financial time series such as volatility, clustering and leptokurtosis. 
Belayneh Debasu and Emmanueal G/Yohannes

\section{The Mean Model}

\section{ARMA Model}

Autoregressive moving average (ARMA) modeling is a specific subset of univariate modeling in which a time series is expressed in terms of past values of itself plus current and lagged values of a 'white noise' error term. $\operatorname{ARMA}(p, q)$ mean model (Box-Jenkins, 1976) is given by:

$$
\mathrm{y}_{\mathrm{t}}=\Phi_{\mathrm{o}}+\sum_{i=1}^{p} \Phi_{\mathrm{i}} \mathrm{y}_{\mathrm{t}-\mathrm{i}}-\sum_{j=1}^{q} \theta_{\mathrm{j}} \varepsilon_{\mathrm{t}-\mathrm{j}}+\varepsilon_{\mathrm{t}}
$$

Where $y_{t}$ is average monthly log return price of selected crops at time $\mathrm{t}, \Phi_{0}$ is constant mean, $\Phi_{1}, \Phi_{2}$, ......, $\Phi_{\mathrm{p}}$ are autoregressive parameters, $\varepsilon_{\mathrm{t}}, \varepsilon_{\mathrm{t}-1}, \ldots$ are white noise error with mean zero and variance and $\sigma^{2}$. and $\theta_{1}, \theta_{2}, \ldots \ldots ., \theta q$ are moving average parameters.

\section{ARIMA Model}

Autoregressive Integrated Moving Average (ARIMA) model was introduced by Box and Jenkins in 1960s for forecasting a variable. ARIMA models consist of unit-root non-stationary time series which can be made stationary by the order of integration ' $d$ '. The general form of ARIMA $(p, d, q)$ is written as:

$$
\Delta^{d} \Psi_{p}(B) Y_{t}=\Phi_{o}+\Theta_{q}(B) \varepsilon_{t},
$$

Where $\psi_{p}(B)=1-\Phi_{1} B-\ldots \ldots-\Phi_{p} B^{p}, \Theta_{q}(B)=1-\theta_{1} B-\ldots \ldots$ $\theta_{q} B^{q}, \Delta=1-B, d$ is the order of integration and $B$ is the backward shift operator.

\section{ARCH Model}

The autoregressive conditional hetroskedasticity model for the variance of the errors, denoted by $\mathrm{ARCH}$ (Q), was proposed by Engle (1982). The conditional variance is given by:

$$
\varepsilon_{\mathrm{t}}=\sigma_{\mathrm{t}} \mathrm{U}_{\mathrm{t}} \text { and } \sigma_{\mathrm{t}}^{2}=\mathrm{\alpha}_{0}+\sum_{i=1}^{Q} \alpha_{\mathrm{i}} \varepsilon_{\mathrm{t}-\mathrm{l}}^{2}
$$

where $U_{t}$ is IID normal residual with mean zero and unit variance and $\sigma_{t}{ }^{2}$ is the conditional variance of the residuals at time $t$, i.e., $\sigma_{t}{ }^{2}=\operatorname{Var}\left(\varepsilon_{t} \mid \varepsilon_{t-1}, \varepsilon_{t-2}, \ldots\right)$. We impose the non-negativity constraints $\alpha_{0}, \alpha_{i}>0 \quad i=1,2$, ...., Q.

\section{GARCH Model}

ARCH model was generalized by Bollerslev (1986) as $\mathrm{GARCH}(\mathrm{P}, \mathrm{Q})$ which allows the conditional variance to be dependent upon previous own lags. Then $\operatorname{ARMA}(p, q)$ - $\mathrm{GARCH}(P, Q)$ model is given by:

$$
\begin{gathered}
\mathrm{y}_{\mathrm{t}}=\Phi_{\mathrm{o}}+\sum_{i=1}^{p} \Phi_{\mathrm{i}} \mathrm{y}_{\mathrm{t}-\mathrm{i}}-\sum_{j=1}^{q} \theta_{\mathrm{j}} \varepsilon_{\mathrm{t}-\mathrm{j}}+\varepsilon_{\mathrm{t}}, \\
\sigma^{2}{ }_{\mathrm{t}}=\mathrm{\alpha}_{0}+\sum_{i=1}^{Q} \alpha_{\mathrm{i}} \varepsilon_{\mathrm{t}-\mathrm{i}}^{2}+\sum_{j=1}^{P} \beta_{\mathrm{j}} \sigma_{\mathrm{t}-\mathrm{j}}^{2}
\end{gathered}
$$

Restrictions: $\alpha_{0}>0, \alpha_{i} \geq 0, \beta_{j} \geq 0$ for $i=1,2, \ldots, Q$ and $j=1,2$, ..., P.

The conditional variance equation of $\mathrm{GARCH}(\mathrm{P}, \mathrm{Q})$ with explanatory variables for wheat seed is given by:

$$
\sigma_{\mathrm{t}}^{2}=\alpha_{0}+\sum_{i=1}^{Q} \alpha_{\mathrm{i}} \varepsilon_{\mathrm{t}-\mathrm{i}}^{2}+\sum_{j=1}^{P} \beta \sigma_{\mathrm{t}-\mathrm{j}}^{2}+\mathbf{v}^{\prime} \mathrm{X}_{t},
$$

where $X_{t}=\left(x_{1 t}, x_{2 t}, . ., X_{k t}\right)^{\prime}$ is a vector of explanatory variables and $\mathbf{Y}=\left(\gamma_{1}, \gamma_{2}, . ., \gamma_{k}\right)^{\prime}$ is a vector of regression coefficients of the explanatory variables.

\section{EGARCH Process}

In order to capture possible asymmetry exhibited by financial time series, a new class of models, termed the
Sci. Technol. Arts Res. J., Oct-Dec 2014, 3(4): 49-58

asymmetric $\mathrm{ARCH}$ models, was introduced. The most popular model proposed to capture the asymmetric effects is Nelson's (1991) exponential GARCH, or EGARCH model. The $\operatorname{ARMA}(p, q)-E G A R C H \quad(P, Q)$ model is given as:

$$
\begin{gathered}
\mathrm{y}_{\mathrm{t}}=\Phi_{\mathrm{o}}+\sum_{i=1}^{p} \Phi_{\mathrm{i}} \mathrm{y}_{\mathrm{t}-\mathrm{i}}-\sum_{j=1}^{q} \theta_{\mathrm{j}} \varepsilon_{\mathrm{t}-\mathrm{j}}+\varepsilon_{\mathrm{t}} \\
\ln \left(\sigma_{\mathrm{t}}{ }^{2}\right)=\alpha_{0}+\sum_{i=1}^{Q} \alpha_{\mathrm{i}}\left|\frac{\varepsilon_{t-i}}{\sigma_{t-i}}\right|+\sum_{i=1}^{R} \lambda_{i}\left(\frac{\varepsilon_{t-i}}{\sigma_{t-i}}\right)+\sum_{j=1}^{P} \beta_{\mathrm{j}} \ln \left(\sigma_{\mathrm{t}-\mathrm{j}}^{2}\right)
\end{gathered}
$$

In this model specification, $\beta_{1}, \beta_{2}, \ldots . \beta_{P}$ are the $\mathrm{GARCH}$ parameters that measure the impact of past volatility on the current volatility.

\section{TGARCH Process}

The TGARCH model with mean and conditional variance equations is given as:

$$
\begin{aligned}
& \mathrm{y}_{\mathrm{t}}=\Phi_{\mathrm{o}}+\sum_{i=1}^{p} \Phi_{\mathrm{i}} \mathrm{y}_{\mathrm{t}-\mathrm{i}}-\sum_{j=1}^{q} \theta_{\mathrm{j}} \varepsilon_{\mathrm{t}-\mathrm{j}}+\varepsilon_{\mathrm{t}}, \\
& \sigma_{\mathrm{t}}{ }^{2}=\mathrm{\alpha}_{0}+\sum_{i=1}^{Q} \alpha_{i} \varepsilon_{\mathrm{t}-\mathrm{i}}^{2}+\sum_{i=1}^{Q} \lambda_{\mathrm{i}} \mathrm{d}_{\mathrm{t}-\mathrm{i}} \varepsilon_{\mathrm{t}-\mathrm{i}}^{2}+\sum_{j=1}^{P} \beta_{\mathrm{j}} \sigma_{\mathrm{t}-\mathrm{j}}^{2} \text {, }
\end{aligned}
$$

where $d_{t-i}=1$ if $\varepsilon_{t-i} \geq 0$, and $d_{t-i}=0$ otherwise. The TGARCH model allows a response of volatility to news with different coefficients for good and bad news.

In this study, the general inflation rate, food inflation rate, non-food inflation rate, exchange rate, saving interest rate, lending interest rate, temperature, rain fall and monthly seasonal dummies were introduced into the conditional variance equation as independent variables in order to determine the impact of these variables on the volatility of average monthly price returns under consideration. The conditional variance equation of $\mathrm{GARCH}(\mathrm{P}, \mathrm{Q})$ with explanatory variables for each cereal crops and pulse seeds is given by:

$$
\sigma_{\mathrm{t}}^{2}=\alpha_{0}+\sum_{i=1}^{Q} \alpha_{i} \varepsilon_{\mathrm{t}-\mathrm{i}}^{2}+\sum_{j=1}^{P} \beta \sigma_{\mathrm{t}-\mathrm{j}}^{2}+\mathbf{v}^{\prime} \mathrm{X}_{t},
$$

where $X_{t}=\left(x_{1 t}, x_{2 t}, \ldots, X_{k t}\right)^{\prime}$ is a vector of explanatory variables and $\mathbf{y}=\left(\gamma_{1}, \gamma_{2}, . ., \gamma_{k}\right)^{\prime}$ is a vector of regression coefficients of the explanatory variables.

Assuming the presence of asymmetric effect on the GARCH family model, the conditional variance equations for $\operatorname{EGARCH}(P, Q)$ and $\operatorname{TGARCH}(P, Q)$ with explanatory variables are given by:

$$
\begin{gathered}
\ln \left(\sigma_{\mathrm{t}}^{2}\right)=\alpha_{0}+\sum_{i=1}^{Q} \alpha_{\mathrm{i}}\left|\frac{\varepsilon_{t-i}}{\sigma_{t-i}}\right|+\sum_{i=1}^{R} \lambda_{i}\left(\frac{\varepsilon_{t-i}}{\sigma_{t-i}}\right)+\sum_{j=1}^{P} \beta_{\mathrm{j}} \ln \left(\sigma_{\mathrm{t}-\mathrm{j}}^{2}\right)+\mathbf{\gamma}^{\prime} \mathrm{X}_{t},[10] \\
\sigma_{\mathrm{t}}{ }^{2}=\alpha_{0}+\sum_{i=1}^{Q} \alpha_{i} \varepsilon_{\mathrm{t}-\mathrm{i}}^{2}+\sum_{i=1}^{Q} \lambda_{\mathrm{i}} \mathrm{d}_{\mathrm{t}-\mathrm{i}} \varepsilon_{\mathrm{t}-\mathrm{i}}^{2}+\sum_{j=1}^{P} \beta_{\mathrm{j}} \sigma_{\mathrm{t}-\mathrm{j}}^{2}+\mathbf{Y}^{\prime} \mathrm{X}_{t} .
\end{gathered}
$$

\section{Assumptions of the Models}

a. The expected value of the error term is zero, i.e. $E\left[\varepsilon_{t}\right]=0$

b. The variance of the error terms is conditionally hetroskedastic.

c. Error terms are independent having normal or student- $t$ or GED distribution with mean zero and variance $\sigma^{2}$.

d. There is no serial autocorrelation among successive error terms.

e. No severe multicollinearity exists among explanatory variables.

\section{Procedures for Model Building}

Testing for the Presence of Unit Root

A test of stationarity (or non-stationarity) that has become widely popular over the past several years is the unit root test. There is a major problem with regression that involves non- stationary variables as the standard 


\section{Belayneh Debasu and Emmanueal G/Yohannes}

errors produced are biased. Due to such bias, conventional criteria used to judge whether there is a casual relationship between the variables are unreliable. Such a regression is what we call spurious regression. It is therefore very important to be able to detect the presence of unit roots in time series. For these tests, the null hypothesis is that the time series has a unit root. The widely used unit-root tests are Augmented Dickey Fuller (ADF) test (Dickey and Fuller, 1979) and Phillips Perron (PP) test (Phillips and Perron, 1987).

\section{The Augmented Dickey Fuller (ADF) Test}

The ADF test is comparable with the simple DF test, but is augmented by adding lagged values of the first difference of the dependent variable as additional repressors which are required to account for possible occurrence of autocorrelation. Consider the AR (p) model:

$$
\begin{aligned}
\nabla y_{t}=\mu & +\alpha y_{t-1}+\sum_{i=2}^{p} \psi_{i} \nabla y_{t-p}+\varepsilon_{\mathrm{t}}, \\
& \text { where } \alpha=-\left(1-\sum_{i=2}^{p} \Phi_{i}\right) \text { and } \psi_{i}=\sum_{j=i}^{p} \Phi_{j} .
\end{aligned}
$$

If the null hypothesis $\mathrm{H}_{0}$ : $\alpha=0$ is not rejected, then we need to difference the data to make it stationary or we need to put a time trend in the regression model to correct for the variables' deterministic trend.

\section{The Phillips and Perron (PP) Test}

An important assumption of the DF test is that the error terms $\varepsilon_{t}$ are independently and identically distributed. The ADF test adjusts the DF test to take care of possible serial correlation in the error terms by adding lagged difference terms of the dependent variable. Phillips and Perron use nonparametric statistical methods to take care of the serial correlation in the error terms without adding lagged difference terms. For details see Perron and $\mathrm{Ng}$ (1996) and Nabeya and Perron (1994).

\section{Testing ARCH Effects}

The Box-Jenkins (1976) approach is based on the assumption that the residuals are homoskedastic (remain constant over time) for ARMA or ARIMA model. But in financial data, ARCH effect is commonly found (Cotter and Stevenson, 2007, Asteriou and Hall, 2007). According to Tsay (2005), there are two available methods to test for $\mathrm{ARCH}$ effects.

\section{(i) Ljung-Box Test:}

It was developed by Box and Pierce (1970) and modified by Ljung and Box (1978) and tests the joint significances of serial correlation in the standardized and squared standardized residuals for the first $k$ lags instead of testing individual significance. They suggested testing the hypothesis:

$$
\begin{gathered}
H_{0}: \rho_{1}=\rho_{2}=\ldots \ldots=\rho_{k}=0 \\
H_{1}: \text { not all } \rho_{j}=0
\end{gathered}
$$

where $\rho_{\mathrm{j}}$ is the ACF at lag $\mathrm{j}=1,2 \ldots \mathrm{k}$.

They suggested the statistic:

$$
\mathrm{Q}(\mathrm{k})=\mathrm{n}(\mathrm{n}+2) \sum_{j=1}^{k} \frac{d_{j}^{2}}{n-j},
$$

where $n$ denotes the length of the series after any differencing and $d_{j}$ denotes the squared residual.

\section{(ii) Lagrange Multiplier (LM) Test:}

This test was suggested by Engle (1982) and used to test the significance of serial correlation in the squared residuals for the first $q$ lags.
Sci. Technol. Arts Res. J., Oct-Dec 2014, 3(4): 49-58

$$
\hat{\varepsilon}_{t}^{2}=\mathrm{\gamma}_{0}+\mathrm{\gamma}_{1} \hat{\varepsilon}_{t-1}{ }^{2}+\ldots+\mathrm{\gamma}_{q} \hat{\varepsilon}_{t-q}{ }^{2}
$$

The null hypothesis is that, $\gamma_{0}=\gamma_{1}=\ldots \ldots .=\gamma_{q}=0$.

The test statistic $\mathbf{n} . \mathbf{R}^{\mathbf{2}}$ is distributed as chi-square with $\mathrm{q}$ degrees of freedom, where $R^{2}$ is the coefficient of determination from equation (13) and $n$ is number of observations. The rejection of the null hypothesis indicates the presence of $A R C H(Q)$ effects.

\section{Test of Normality}

When dealing with GARCH family models, the data is first tested for normality (i.e. whether the returns follow a normal distribution). The test is named after Jarque and Bera (1982).

$\mathrm{H}_{0 \text { : }}$ the observations come from a normal distribution. The test statistic is:

$$
\mathrm{JB}=\frac{n}{6} *\left(\mathrm{~S}^{2}+\frac{(\mathrm{k}-3)^{2}}{4}\right)
$$

where $\mathrm{n}$ is the number of observations, $\mathrm{S}$ is the sample skewness and $\mathrm{K}$ is the sample kurtosis. Under the null hypothesis, the Jarque-Bera statistic is distributed as chi-square distribution with two degrees of freedom.

\section{Model Order Selection in GARCH Family Model}

A model selection criterion considers the "best approximating model" from a set of competing models.An important practical problem is the determination of the $A R C H$ order $Q$ and the GARCH order $P$ for a particular series. Since GARCH models can be treated as ARMA models for squared residuals, traditional model selection criteria such as the Akaike information criterion (AIC) proposed by Akaike (1974) and the Schwartz Bayesian information criterion (SBIC) proposed by Schwartz (1989) can be employed to identify the optimal lag specification for the model. These criteria are computed using the loglikelihood estimates. Given the criterion values of two or more models, the model having minimum AIC or BIC is most representative of the true model and, on this account, may be interpreted as the best approximating model among those being considered (Dayton, 2003).

The formal expressions for the above criteria in terms of the log- likelihood are:

$$
\begin{aligned}
& A I C=-2 \ln (L)+2 K \\
& B I C=-2 \ln (L)+K \cdot \ln (n)
\end{aligned}
$$

where $n=$ number of observations

$\mathrm{K}=$ number of parameters estimated

$L=$ value of the likelihood function $\left(\log L\left(\sigma_{t}^{2}\right)\right)$

The main reason for preferring the use of a model selection procedure such as BIC in comparison to traditional significance tests is the fact that a single holistic decision can be made concerning the model that is best supported by the data in contrast to what is usually a series of possibly conflicting significance tests.

\section{Model Parameter Estimation}

Under the presence of ARCH effects, the OLS estimation is not efficient since volatility models used are non-linear in conditional variance though linear in mean. As many studies indicated, the commonly used method known as the maximum likelihood estimation has been employed in GARCH family model. Financial time series data possess volatility clustering and leptokurtosis characteristics which lead to the use of different distributional assumptions for residuals such as: - 


\section{Belayneh Debasu and Emmanueal G/Yohannes}

Normal, Student-t and GED. Thus, in this study the Gaussian (Normal), Student-t distribution and the GED were considered for GARCH family model parameter estimation and the appropriate distributions for the residuals were identified based on robust estimation. The estimation of conditional volatility models are typically performed by MLE procedures in Bollerselv and Wooldridge (1992).

Maximum likelihood method follows the following steps:

1. Specify the appropriate equations for the conditional mean and the variance.

2. Specify the log-likelihood function of the model to maximize.

3. Use regression to get initial guesses for the mean parameters from mean equation.

4. Choose some initial guesses for the conditional variance parameters.

5. Specify a convergence criterion.

Maximization of the likelihood function of the model analytically in terms of its parameter is impossible because of non-linearity of $\mathrm{GARCH}$ family models

\section{Model Adequacy Checking}

After a GARCH family model has been fit to the data, the adequacy of the fit has been evaluated using a number of graphical and statistical diagnostics.

The followings are the methods for model adequacy checking that were used in this study:-

1. The ACFs of the residuals should be indicative of a white noise process.

2. The standardized residuals should be normally distributed. This was checked through Jarque-Bera test.

3. The Ljung-Box test is one of the widely used tests for the appropriateness of the fitted model; to test whether the model of the mean is appropriately specified and to test for the remaining $\mathrm{ARCH}$ effects

4. Evaluating the performance of different forecasting models: the most widely used statistical evaluation measures are MAE, RMSE, MAPE and Theils- $U$ Inequality Coefficient (TU). These are applied to measure the forecasting accuracy of the $\mathrm{ARCH}$ GARCH model in this study.
Sci. Technol. Arts Res. J., Oct-Dec 2014, 3(4): 49-58

\section{Prediction using GARCH Family Models}

An important task of modeling conditional volatility is to generate forecasts for both the future value of a financial time series as well as its conditional volatility. Conditional variance forecasts from GARCH family models are obtained with similar approach to forecasts from ARMA models by iterating with the conditional expectations operator. In other words, when the estimation of the unknown parameters is done, estimates of the standard deviation series can be calculated recursively via the definition of the Conditional variance for the GARCH (P, Q) family process which helps to examine the past behavior of average monthly domestic price volatilities of the series under consideration.

\section{Statistical Analysis}

The return series were constructed for each of the prices to allow a market wide measure of volatility to be examined. The data analysis is carried out using EViews 7 and STATA 11 software.

\section{RESULTS}

Figure 1 is a plot of average monthly price trend of pulses. It can be observed that monthly prices show an increasing trend over the study period.

The empirical result shows that the average monthly price for bean and pea are 4.4577 and 5.1270 with standard deviation 3.2850 and 3.4921, respective of their order (Table 1). In the case of log return series, the coefficients of kurtosis exceed three, indicating that the log return series are peaked relative to the normal distribution (that is, leptokurtic). Moreover, the series exhibit positive skewness. The Jarque-Bera test of normality rejects the normality of all the series under consideration.

Table 2 displays summary statistics for each of the explanatory variables. The sample mean (SD) was estimated to be about 10.901 (3.186) for exchange rate in birr, $3.5906(0.7596)$ for saving interest rate, 11.161 (0.744) for lending interest rate. Moreover, mean (SD) was estimated to be about 15.82 (14.87) for general inflation rate, 19.21 (21.04) for food inflation rate, 11.914 (9.089) for non-food inflation rate, 18.394 (1.4249) for average monthly temperature and 3.0393 (3.3705) for average monthly rain fall.

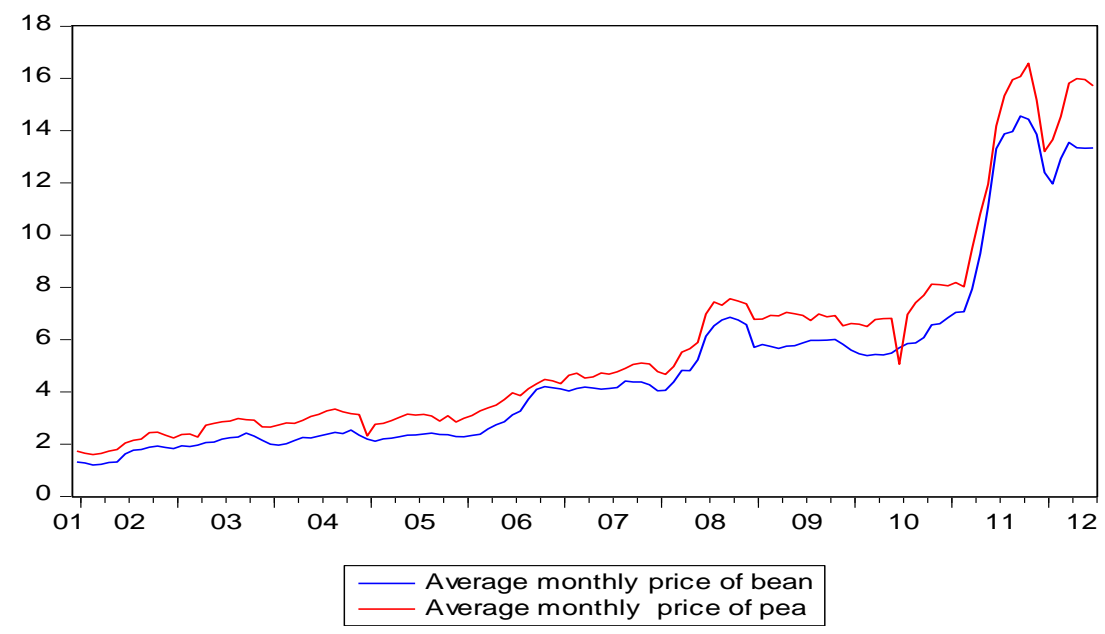

Figure 1: Average monthly price trend of Bean and Pea 
Table 1: Summary results for average monthly price and Log-return series for Bean and Pea

\begin{tabular}{lcccc}
\hline \multirow{2}{*}{ Statistics } & \multicolumn{2}{c}{ Average monthly price } & \multicolumn{2}{c}{ Log-return series } \\
\cline { 2 - 5 } & bean & pea & bean & pea \\
\hline Mean & 4.4577 & 5.1270 & 0.0203 & 0.0176 \\
Median & 3.8211 & 4.1277 & 0.0137 & 0.0171 \\
Maximum & 13.4914 & 16.6800 & 0.3694 & 0.4694 \\
Minimum & 0.9214 & 1.3566 & -0.1168 & -0.2758 \\
Std. Dev. & 3.2850 & 3.4921 & 0.0677 & 0.1172 \\
skewness & 1.4803 & 1.4810 & 1.3859 & 0.5334 \\
kurtosis & 4.3961 & 4.5415 & 7.7633 & 5.3852 \\
Jarque-Bera & 56.7036 & 59.0032 & 159.4429 & 35.8467 \\
P-value & 0.0000 & 0.0000 & 0.0000 & 0.0000 \\
\hline
\end{tabular}

Table 2: Summary results for covariates

\begin{tabular}{ccccccccc}
\hline statistics & $\begin{array}{c}\text { Exchange } \\
\text { rate }\end{array}$ & $\begin{array}{c}\text { Saving } \\
\text { Interest } \\
\text { rate }\end{array}$ & $\begin{array}{c}\text { Lending } \\
\text { interest } \\
\text { rate }\end{array}$ & $\begin{array}{c}\text { General } \\
\text { inflation } \\
\text { rate }\end{array}$ & $\begin{array}{c}\text { Food } \\
\text { inflation } \\
\text { rate }\end{array}$ & $\begin{array}{c}\text { Non-food } \\
\text { inflation } \\
\text { rate }\end{array}$ & $\begin{array}{c}\text { Temperature } \\
\text { (in }{ }^{\mathbf{c}} \text { ) }\end{array}$ & $\begin{array}{c}\text { Rain fall } \\
\text { (in mm) }\end{array}$ \\
\hline Mean & 10.901 & 3.5906 & 11.161 & 15.815 & 19.21 & 11.914 & 18.394 & 3.039 \\
Median & 8.931 & 3.00 & 10.75 & 12.20 & 14.10 & 12.00 & 18.30 & 1.50 \\
Minimum & 8.645 & 3.00 & 10.500 & -7.30 & -14.00 & -2.200 & 13.6099 & 0.00 \\
Maximum & 17.846 & 6.00 & 12.75 & 64.20 & 91.70 & 29.50 & 21.7620 & 13.873 \\
St. dev. & 3.186 & 0.7596 & 0.744 & 14.867 & 21.035 & 9.0885 & 1.4249 & 3.3705 \\
\hline
\end{tabular}

\section{Tests of Stationarity}

Before considering volatility models, the first logical step is to check the stationarity of the average monthly price using ADF test and PP unit root test. In ADF test, the null hypothesis of unit root is rejected if the test statistic is less than the critical value or the $P$-value is less than the level of significance $(\alpha=0.05)$. As can be seen from the table 3 , the null hypothesis of unit root would not be rejected, that is, there is a unit root problem in each of the series indicating that each average monthly price series is non-stationary.
The table 4 shows that all the t-statistics are less than the critical values. These indicate that the null hypothesis of unit root would be rejected in all of the four cases. Hence the log return series are stationary.

All the variables except saving interest rate are nonstationary at level. However, except saving interest rate all the variables are stationary after first difference as shown in Table 5, implying that all explanatory variables are integrated of order one.

Table 3: ADF unit root test at level for average monthly prices

\begin{tabular}{cccccc}
\hline Prices & Test Statistics & $\mathbf{1 \%}$ critical value & $\mathbf{5 \%}$ critical value & $\mathbf{1 0} \%$ critical value & P-value \\
\hline Bean & -0.0103 & -3.4833 & -2.8846 & -2.5791 & 0.9552 \\
Pea & 0.3528 & -3.4833 & -2.8846 & -2.5791 & 0.9801 \\
\hline
\end{tabular}

Table 4: ADF unit root test at level for average monthly price of log-return series

\begin{tabular}{cccccc}
\hline Log-returns & Test Statistics & $\mathbf{1 \%}$ critical value & $\mathbf{5 \%}$ critical value & $\mathbf{1 0 \%}$ critical value & P-value \\
\hline Bean & -8.0807 & -3.4833 & -2.8846 & -2.5791 & $0.0000^{*}$ \\
Pea & -16.22092 & -3.4833 & -2.8846 & -2.5791 & $0.0000^{*}$ \\
\hline \multicolumn{5}{c}{ Statistically significant }
\end{tabular}

Table 5: ADF unit root test of the first difference of explanatory variables

\begin{tabular}{lccccc}
\hline Explanatory variable & ADF test statistic & $\mathbf{1 \%}$ critical value & $\mathbf{5 \%}$ critical value & $\mathbf{1 0 \%}$ critical value & p-value \\
\hline Exchange rate & -10.4595 & -3.4833 & -2.8846 & -2.5791 & $0.0000^{*}$ \\
Lending interest rate & -20.0609 & -3.4833 & -2.8846 & -2.5791 & $0.0000^{*}$ \\
General inflation rate & -5.8561 & -3.4833 & -2.8846 & -2.5791 & $0.0000^{*}$ \\
Food inflation rate & -5.7294 & -3.4833 & -2.8846 & -2.5791 & $0.0000^{*}$ \\
N-food inflation rate & -5.7294 & -3.4833 & -2.8846 & -2.5791 & $0.0000^{*}$ \\
Temperature & -10.2286 & -3.4880 & -2.8867 & -2.5802 & $0.0000^{*}$ \\
Rain fall & -21.0537 & -3.4880 & -2.8867 & -2.5802 & $0.0000^{*}$ \\
\hline
\end{tabular}

Statistically significant

\section{Estimation of Mean Equation}

In the specification of the mean equation, lower order ARMA models are often considered, say, the twenty five combinations of AR (0-4) and MA (0-4). Optimal lag length was selected based on the minimum BIC provided that no serial autocorrelation exists in the residuals from the specified mean model. The presence of autocorrelation in the residuals was tasted using the Lagrange Multiplier
(LM) test for each of the mean equations considered. Only models with no remaining serial correlations are considered as candidate models.

Among the candidate mean models for the price return series of bean, ARMA $(4,4)$ has the smallest BIC and exhibits no serial autocorrelation. 


\section{Belayneh Debasu and Emmanueal G/Yohannes}

Similarly, ARMA $(1,0)$ has found to have the smallest $\mathrm{BIC}$ for the return series of pea. The fitted mean equations are shown in Tables 6 and 7.

Table 6: ARMA $(4,4)$ mean equation for average monthly price return series of Bean

\begin{tabular}{ccccc}
\hline Variable & Coefficient & Std. Error & t-Statistic & Prob. \\
\hline C & 0.019799 & 0.006370 & 3.108349 & 0.0024 \\
$\mathrm{AR}(1)$ & 0.306711 & 0.067574 & 4.538884 & 0.0000 \\
$\mathrm{AR}(2)$ & 0.718954 & 0.071917 & 9.996980 & 0.0000 \\
$\mathrm{AR}(3)$ & -0.157235 & 0.068252 & -2.303762 & 0.0231 \\
$\mathrm{AR}(4)$ & -0.692221 & 0.064204 & -10.78162 & 0.0000 \\
$\mathrm{MA}(1)$ & -0.046703 & 0.026910 & -1.735490 & 0.0854 \\
$\mathrm{MA}(2)$ & -0.854187 & 0.033694 & -25.35109 & 0.0000 \\
$\mathrm{MA}(3)$ & -0.059356 & 0.025937 & -2.288484 & 0.0240 \\
$\mathrm{MA}(4)$ & 0.958533 & 0.021534 & 44.51244 & 0.0000 \\
\hline
\end{tabular}

Table 7: ARMA $(1,0)$ mean equation for average monthly price return series of $\mathrm{Pea}$

\begin{tabular}{ccccc}
\hline Variable & Coefficient & Std. Error & t-Statistic & Prob. \\
\hline C & 0.017884 & 0.007229 & 2.473819 & 0.0147 \\
$\mathrm{AR}(1)$ & -0.362475 & 0.083995 & -4.315441 & 0.0000 \\
\hline
\end{tabular}

\section{Testing for ARCH Effects}

The ARCH LM test helps to test the hypothesis that there is no ARCH effect up to lag Q. Table 8 shows the results of $A R C H$ LM test for lags 1,2 and 3 for monthly price return series. The test for the null hypothesis of no $\mathrm{ARCH}$ effects using Engle LM test and F-test confirmed the presence of $\mathrm{ARCH}$ (1) effects in the residuals from mean equations for bean and pea average monthly price returns. These results indicate that the respective log return series are volatile and need to be modeled using GARCH family models.
Sci. Technol. Arts Res. J., Oct-Dec 2014, 3(4): 49-58

Optimal Order Selection and Parameter Estimation of GARCH Family Model

The optimal lag for GARCH family models has to be determined prior to the construction of the final model to investigate the determinants of monthly price volatility. Since there is a consensus that $\operatorname{GARCH}(1,1)$ family model is the most convenient specification in the financial literature (Bollerslev et al., 1992 and Lee and Hansen, 1994), the $\operatorname{GARCH}(1,1)$ model is compared to various higher-order models of volatilities based on the minimum AIC and BIC.

After testing for different orders of $P$ and $Q$ of $\mathrm{GARCH}$ family, it was found that $\operatorname{EGARCH}(1,3)$ under Normal distributional assumption for residuals, $\operatorname{EGARCH}(2,1)$ under Student-t distributional assumption for residuals and $\operatorname{EGARCH}(2,3)$ under GED distributional assumption for residuals for the price volatility of bean and $\operatorname{EGARCH}(1,1)$ under Normal distributional assumption for residuals, $\operatorname{EGARCH}(1,2)$ under Student-t distributional assumption for residuals and $\operatorname{EGARCH}(2,1)$ under GED distributional assumptions for residual for the price volatility of pea were found to be the best models to describe the data as they possess minimum BIC. The summary results are displayed in Table 9.

Moreover, to select the appropriate error distribution for selected asymmetric GARCH class models among normal, Student-t and GED distributions, the four forecast accuracy statistics: RMSE, MAE, MAPE and Theil Inequality coefficient were applied using in-sample forecast. The results show that ARMA(4,4)-EGARCH $(2,3)$ model with GED for residuals and $\operatorname{ARMA}(1,0)$ EGARCH $(1,2)$ model with student-t for residuals for bean and pea, respectively perform best as compared to others as they possess the smallest forecast error measures in the majority of the statistics considered. The parameters in the mean and variance equations are estimated using the maximum likelihood (ML) method. The results are shown in Table 10.

Table 8: ARCH LM test summary statistics

\begin{tabular}{ccccccc}
\hline Item & $\mathbf{A R C H}(\mathbf{Q})$ & $\boldsymbol{X}^{2}$ statistic & p-value & F-statistic & p-value & BIC \\
\hline \multirow{6}{*}{ Bean } & $\mathrm{ARCH}(1)$ & 9.4601 & 0.0021 & 10.0709 & 0.0019 & -7.6773 \\
& $\mathrm{ARCH}(2)$ & 2.1749 & 0.0371 & 1.0793 & 0.0343 & -7.5575 \\
& $\mathrm{ARCH}(3)$ & 2.1551 & 0.5408 & 0.7070 & 0.5497 & -7.5093 \\
\hline \multirow{6}{*}{ Pea } & $\mathrm{ARCH}(1)$ & 13.5135 & 0.0032 & 14.9091 & 0.0002 & -4.7987 \\
& $\mathrm{ARCH}(2)$ & 3.2218 & 0.1997 & 1.6138 & 0.2034 & -4.7549 \\
& $\mathrm{ARCH}(3)$ & 3.4957 & 0.3213 & 1.1602 & 0.3280 & -4.7117 \\
\hline
\end{tabular}

Table 9: Optimal lag selected based on BIC under different distributional assumptions of residuals

\begin{tabular}{|c|c|c|c|c|}
\hline Variable & Model & Error Distribution & BIC & Asymmetric term ( $\alpha=5 \%)$ \\
\hline \multirow{3}{*}{ bean } & $\operatorname{ARMA}(4,4)-\mathrm{EGARCH}(1,3)$ & Normal & -2.2486 & significant \\
\hline & $\operatorname{ARMA}(4,4)-\operatorname{EGARCH}(2,1)$ & Student- $t$ & -2.2141 & Not significant \\
\hline & $\operatorname{ARMA}(4,4)-\operatorname{EGARCH}(2,3)$ & GED & -2.4844 & significant \\
\hline \multirow{3}{*}{ pea } & $\operatorname{ARMA}(1,0)-E G A R C H(2,2)$ & Normal & -1.0630 & Significant \\
\hline & $\operatorname{ARMA}(1,0)-\operatorname{EGARCH}(1,2)$ & Student-t & -1.0828 & significant \\
\hline & $\operatorname{ARMA}(1,0)-\operatorname{EGARCH}(2,1)$ & GED & -1.0683 & Not significant \\
\hline
\end{tabular}


Table 10: ML parameter estimates of the volatility models for Wheat, Bean and Pea

\begin{tabular}{|c|c|c|c|c|}
\hline \multirow{2}{*}{ Parameter } & \multicolumn{2}{|c|}{ Bean } & \multicolumn{2}{|c|}{ Pea } \\
\hline & Mean ( $P$-value) & Variance ( $P$-value) & Mean ( $P$-value) & Variance ( $P$-value) \\
\hline Constant & $0.0167(0.000)^{\star *}$ & $5.0892(0.000)^{* \star}$ & $0.0685(0.000)^{* *}$ & $-3.0820(0.0017)^{\star \star}$ \\
\hline $\mathrm{AR}(1)$ & $0.1578(0.0001)^{* *}$ & & $-0.1602(0.028)^{*}$ & \\
\hline $\mathrm{AR}(2)$ & $0.3737(0.0009)^{* *}$ & & & \\
\hline $\operatorname{AR}(3)$ & $0.0712(0.0074)^{\star *}$ & & & \\
\hline $\mathrm{AR}(4)$ & $0.0132(0.0000)^{* *}$ & & & \\
\hline $\mathrm{MA}(1)$ & $-0.208(0.0031)^{\star \star}$ & & & \\
\hline $\mathrm{MA}(2)$ & $-0.283(0.3621)$ & & & \\
\hline $\mathrm{MA}(3)$ & $0.2721(0.0010)^{\star *}$ & & & \\
\hline $\mathrm{MA}(4)$ & $0.1080(0.0064)^{* *}$ & & & \\
\hline $\mathrm{ARCH}(-1)$ & & $0.9621(0.000)^{* *}$ & & $0.4030(0.0019)^{\star *}$ \\
\hline $\mathrm{ARCH}(-2)$ & & $0.3435(0.003)^{\star \star}$ & & \\
\hline Asymmetric $(-1)$ & & $1.3167(0.001)^{\star *}$ & & $0.6067(0.0000)^{\star *}$ \\
\hline Asymmetric (-2) & & $0.8162(0.000)^{\star *}$ & & \\
\hline EGARCH $(-1)$ & & $0.5174(0.0182)^{*}$ & & $-0.5212(0.0405)^{*}$ \\
\hline EGARCH (-2) & & $0.8380(0.000)^{\star *}$ & & $0.4121(0.0294)^{*}$ \\
\hline EGARCH (-3) & & $0.2110(0.000)^{\star \star}$ & & \\
\hline Exchange rate & & $1.9877(0.0351)^{*}$ & & $1.3425(0.000)^{\star *}$ \\
\hline Saving interest rate & & $-0.3054(0.0326)^{*}$ & & $-0.6216(0.2262)$ \\
\hline Lending interest rate & & $-2.6011(0.0502)$ & & $2.6144(0.2586)$ \\
\hline General inflation rate & & $0.3076(0.002)^{\star \star}$ & & $0.2480(0.0282)^{*}$ \\
\hline Food inflation rate & & $0.1213(0.007)^{\star \star}$ & & $0.2899(0.0000)^{\star *}$ \\
\hline N-Food inflation rate & & $0.4922(0.0421)^{*}$ & & $0.0544(0.9250)$ \\
\hline Temperature & & $-0.4824(0.6472)$ & & $0.2673(0.0038)^{* *}$ \\
\hline Rain fall & & $-0.1314(0.0359)^{*}$ & & $-0.5914(0.0135)^{\star}$ \\
\hline February & & $0.4076(0.0108)^{*}$ & & $-0.9004(0.0033)^{\star *}$ \\
\hline March & & $-0.2121(0.006)^{\star *}$ & & $-1.1125(0.0020)^{\star *}$ \\
\hline April & & $-0.5478(0.001)^{* *}$ & & $0.3230(0.8362)$ \\
\hline May & & $-0.5190(0.4479)$ & & $0.5762(0.7251)$ \\
\hline June & & $1.0782(0.1562)$ & & $2.2574(0.1407)$ \\
\hline July & & $4.4911(0.000)^{\star \star}$ & & $2.3735(0.0000)^{* *}$ \\
\hline August & & $0.7770(0.0291)^{*}$ & & $1.7715(0.0100)^{*}$ \\
\hline September & & $0.0913(0.9399)$ & & $2.2717(0.0070)^{\star *}$ \\
\hline October & & $-0.6234(0.002)^{\star *}$ & & $2.1119(0.2272)$ \\
\hline November & & $0.6394(0.4920)$ & & $2.5899(0.1374)$ \\
\hline December & & $1.7450(0.0816)$ & & $1.4327(0.0067)^{\star *}$ \\
\hline
\end{tabular}

${ }^{*}$ Significance at the $5 \%$ level and ${ }^{* *}$ significance at the $1 \%$ level.

\section{DISCUSSION}

\section{Monthly Price Return Series for Bean}

From the results, exchange rate, general inflation, food inflation and non-food inflation have positive and significant effect on the price volatility of bean. An increase in exchange rate, general inflation, food inflation and non-food inflation leads to increase in the volatility of average monthly price of bean. In contrast, saving interest rate and average rainfall had significant negative effect. The rainfall result is in line with the findings by Alisher (2012). From the observed results of seasonal dummies, prices in February, July and August have an increasing significant effect, while March, April and October have decreasing effect.

The results indicate that EGARCH (-1), EGARCH (-2) and EGARCH $(-3)$ terms are positive and statistically significant at the $5 \%$ level. The positive coefficient of the $\mathrm{EGARCH}(-1), \mathrm{EGARCH}(-2)$ and $\mathrm{EGARCH}(-3)$ terms show that the 1-, 2- and 3- month lagged price volatility of bean leads to an increase in current month volatility. Also, 1- and 2- month lagged shocks (ARCH (-1) and ARCH (-2) terms) of the average monthly price of bean have statistically significant effect. Similarly, the asymmetric term was positive and statistically significant at the $1 \%$ level of significance. Thus, bad news had larger impact on the price volatility than good news.

\section{Monthly Price Return Series for Pea}

The results of pea also indicate that exchange rate, general inflation, food inflation and temperature are positively significant, while rainfall negatively affects price volatility of pea. The prices in July, August, September and December have a positive significant effect. On the other hand, prices in February and March affect the price volatility of pea negatively.

The EGARCH $(-1)$ term has a negative effect on the current price volatility of pea. This result is not in line with the findings by Greene (2003). And 1- month lagged shock (ARCH $(-1)$ term) of the average price of pea had a positive significant effect. Likewise, the asymmetric $(-1)$ term was positively significant at the $1 \%$ level. 


\section{Belayneh Debasu and Emmanueal G/Yohannes}

\section{Checking Adequacy of Fitted Models}

Various diagnostic tests were performed to check the appropriateness of the fitted models. The Ljung-Box $Q(k)$ test indicates that autocorrelations in the standardized residuals are not significantly different from zero for the first 32 lags for bean and pea return series, indicating that the residuals are uncorrelated (white noise).

The tests for the remaining $\mathrm{ARCH}$ effect at time lag 1, 2 and 3 of squared residuals shows no remaining $A R C H$ effect as the $p$-values from both chi-square and $F$ tests are greater than $5 \%$.

The results reveal that the coefficients of skewness were 0.2988 and 0.0865 and the coefficients of kurtosis were 2.6791 and 2.7501 for bean and pea, respectively. The Jarque-Bera test statistics were insignificant in all cases implying that the residuals were approximately
Sci. Technol. Arts Res. J., Oct-Dec 2014, 3(4): 49-58

normally distributed. Thus, the volatility models fitted for average monthly prices were good fit for the data.

\section{In-sample Forecast of Average Monthly Price Volatility Using EGARCH Fitted Models}

Using the fitted volatility models for average monthly price of wheat, bean and pea, the volatility of prices (using variance as a volatility measure) was forecasted. The dynamic in-sample forecasts are presented in Figure 2 and Figure 3.

It can be observed that high price volatility was observed during 2008-2012 for bean. Also high price volatility values were observed during the year 2008 and 2011- 2012 for pea. Moreover, it can be seen that the average monthly price of pea shows more volatility (in particular around 2008) as compared to the other monthly price series.

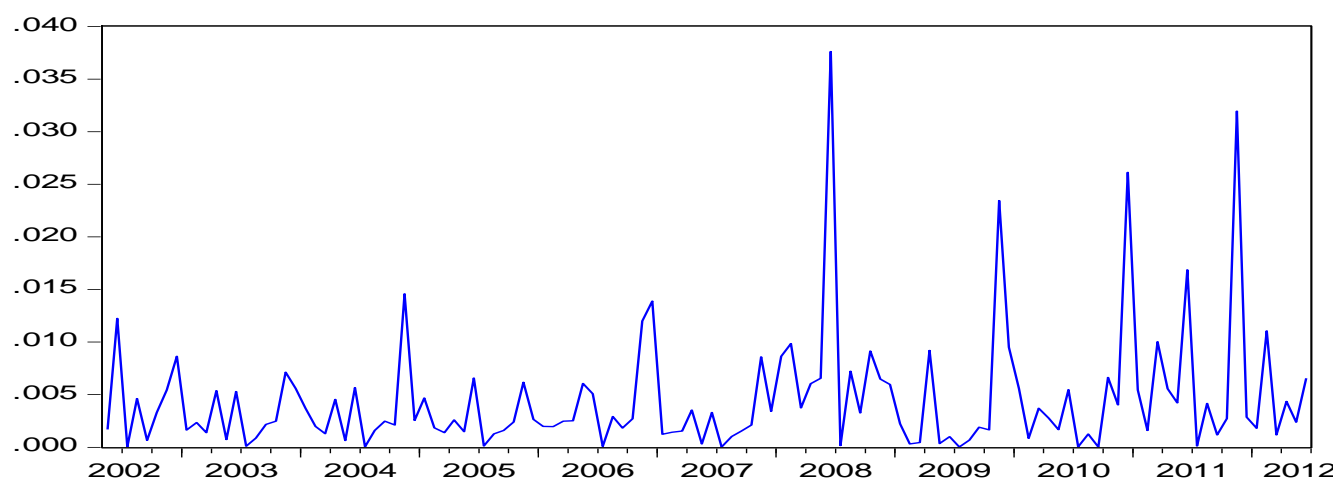

Figure 2: In sample forecast of average monthly price volatility for Bean

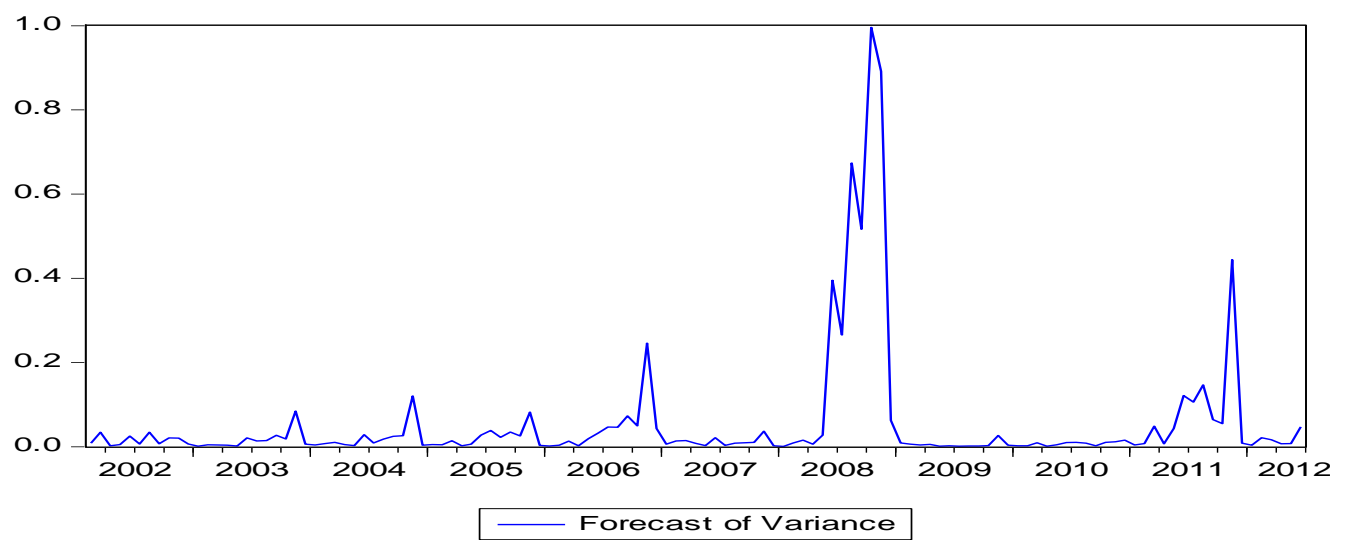

Figure 3: In sample forecast of average monthly price volatility for Pea

\section{CONCLUSIONS}

This study considered the average monthly price volatility and its determinants pulse (bean and pea) from December 2001 to June 2012 G.C in Amhara National Regional State (ANRS). From the empirical results, it can be concluded that average price return series of, bean and pea show the characteristics of financial time series such as volatility clustering, leptokurtic distributions and asymmetric effect. This justifies the use of the GARCH family models.

The forecast performances of the models were evaluated using the MAE, MAPE, RMSE and Theil inequality coefficient. Asymmetric EGARCH model with GED and Student-t distributional assumption for residuals was found to be the best fit model. That is, ARMA $(4,4)$ $\operatorname{EGARCH}(2,3)$ model with GED for bean and ARMA $(1,0)$ $\operatorname{EGARCH}(1,2)$ model with student-t for pea were found to be the best fit models for average monthly price of log return series.

Monthly average price volatility of bean had a significant positive relationship with exchange rate, general inflation and food inflation rate. Thus, an increase in exchange rate, general inflation rate and food inflation rate push up the average price volatility of bean. Also inflation of non-food items had a positive significant effect on the average price volatility of bean. On the other hand, price volatility of bean had a negative relationship with saving interest rate and rainfall. The volatility in the average price of pea had a significant positive relationship 


\section{Belayneh Debasu and Emmanueal G/Yohannes}

with exchange rate, general inflation, food inflation and temperature. Rainfall was negatively affecting the volatility of average price of pea.

Some of the monthly dummies were found to be significant. This indicates that price volatility has seasonal pattern.

In all the series considered, the asymmetric term (s) was (were) found to be positive and significant. This is an indication that unanticipated increase in prices had larger impact on price volatility than unanticipated decrease of the same. Moreover, the EGARCH terms were significant in all volatility models considered. This is a strong evidence of the presence of volatility spillover from one period (month in our case) to another.

\section{ACKNOWLEDGEMENTS}

We are very grateful to Arba Minch University for financial support to my M.Sc. studies at Gondar University through the whole academic years. My sincere thanks go to the National Bank of Ethiopia, Central Statistical Agency and National Metrological Agency for their cooperation at data collection stage.

\section{REFERENCE}

Akaike, H. (1974). Anew Look at Statistical Model Identification. IEEE Transactions on Automatic Control AC 19(6): 716-723.

Alisher Mirzabaev (2012). Climate volatility and change in central Asia: Economic impacts and adaptation.

ANRS-BoFED (2011). Amhara National Regional StateBureau of Finance and Economic.

Asteriou, D. and Hall, S.G. (2007). Applied Econometrics: A Modern Approach Using Eviews and Microfit: Revised Edition, Hampshire, Palgrave Macmillan.

Bollerslev, T. and J.M. Wooldridge (1992), Quasimaximum likelihood estimation and inference in dynamic models with time-varying covariances, Econometric Reviews 11: 143-173.

Bollerslev, T., Chou, R. Y and Kroner, K.F. (1992). ARCH Modeling in Finance. A Review of Theory and Empirical Evidence. Journal of Economics 52: 5-59.

Bollersslev. T. and Taylor (1986). Generalized Auto regressive Conditional Heteroskedasticity. Journal of Econometrics 31: 307-328.

Box, G.E.P. and Jenkins, G.M. (1976). Time Series Analysis, Forecasting and Control. Revised Edition, Holden Day.

Dayton, C.M. (2003). Model Comparison Using Information Measures. Journal of Modern Applied Statistical Methods 2(2): 281-292.
Sci. Technol. Arts Res. J., Oct-Dec 2014, 3(4): 49-58

Dickey, D.A. and Fuller, W.A. (1979). Distributions of the Estimators for Autoregressive Time Series with a Unit Root. Journal of the American Statistical Association 74: 427-431.

Engle, R.F. (1982). Autoregressive Conditional Heteroskedasticity with Estimates of the Variance of United Kingdom Inflation. Journal of Econometrics 50: 987-1007.

FAO (2011). Responding to Global Food Price Volatility and its Impact on Food Security.

Fryzlewicz, P. (2007). Lecture Notes: Financial time series $\mathrm{ARCH}$ and GARCH models, Department of Mathematics, University of Bristol, Bristol BS8 1TW, UK. p.z.fryzlewicz@bristol.ac.uk, http://www.maths. bris.ac.uk/ mapzf/.

Hoddinott, J. (2006). Shocks and their consequences across and within households in rural Zimbabwe. Journal of Development Studies 42(2): 301-321.

IMF (2009). The Federal Democratic Republic of Ethiopia: Selected Issues Series, International Monetary Fund Country Report, No. 08/259, pp. $35 f$.

Jordaan, H., Jooste, B.A. and Alemu, Z.G. (2007). Measuring the Price Volatility of Certain Field Crops in South Africa: Using the ARCH/GARCH Approach. Journal of agriculture 46.

Lee, S.W., Hansen, B.E. (1994). Asymptotic properties of the maximum likelihood estimator and test of the stability of parameters of the GARCH and IGARCH models. Econometric Theory 10: 29-52.

Ljung, G. and Box, G. E. P. (1978): On a Measure of Lack of Fit in Time Series Models, Biometrika, 66, 67-72.

Nabeya, S. and Perron, P. (1994). Local asymptotic distribution related to the $A R(1)$ model with dependent errors. Journal of Econometrics 62(2): 229-264.

Nelson, D.B. (1991). Conditional Heteroskedasticity in Asset Returns. A New Approach Econometrician 59(2): 347-370.

Perron P. and Ng. S. (1996). Useful modifications to some unit root tests with dependent errors and their local asymptotic properties. Review of Economic Studies 63: $435-463$

Phillips, C.B. and Perron, P. (1987). Testing for a Unit Root in Time Series Regression. Biometrics 75: 335346 .

Shewartz, G. W. (1989). Why Does Stock Market Volatility Change over Time? Journal of Finance 44(5): 11151153.

Tsay, R.S. (2005). Analysis of Financial Time Series, $2^{\text {nd }}$ Edition. John Wiley and Sons, New York. 